IMAFRONTE- $\mathrm{N}^{\mathrm{o}} 27.2020$, pp. 1-16

ISSN: 0213-392X / eISSN: 1989-4562

DOI: https://doi.org/10.6018/imafronte.433751

\title{
LA PROPAGANDA COMERCIAL COMO TRANSMISORA DE ELEMENTOS IDENTITARIOS: ALGUNOS EJEMPLOS DE LA EPHEMERA MURCIANA A PRINCIPIOS DEL SIGLO XX ${ }^{1}$
}

\author{
COMMERCIAL ADVERTISING AS A TRANSMITTER OF IDENTITY \\ ELEMENTS: SOME EXAMPLES OF THE MURCIAN EPHEMERA AT THE \\ BEGINNING OF THE 20TH CENTURY
}

JOSÉ MIGUEL LÓPEZ CASTILLO

Universidad de Murcia

Recibido: 14-01-20 / Aprobado: 23-04-20

\section{RESUMEN}

Uno de los apartados menos tratados de las representaciones visuales de Murcia ha sido el de la ephemera comercial. Por tal motivo, dado su uso limitado y efímero, en muchas ocasiones no se le ha considerado como un apartado estimable en la historia del arte. Pero lo cierto es que las etiquetas de fábricas de conservas, frutas, licores y otros establecimientos, desde los últimos años del siglo XIX y la primera mitad del

\begin{abstract}
$\mathrm{XX}$, en base al diseño difundieron los elementos identitarios más significativos de este territorio por toda España y el resto del mundo. En la mayoría de casos, la marca publicitaria estaba basada en estampas e imágenes del Costumbrismo romántico murciano que ya se habían consolidado durante el ochocientos para la demanda social de esa corriente; en otros casos se fueron adaptando a los nuevos criterios estéticos del siglo XX. Finalmente, esta forma de publicitar cada producto ayudó a patentar la
\end{abstract}

\footnotetext{
${ }^{1}$ Este estudio se ha realizado dentro del contexto de la Beca FPU (FPU17/00039) del Ministerio de Educación, Cultura y Deportes y del Proyecto de Investigación I+D Excelencia HAR2017-83666-P, El documental de arte en España (1939-1975), del Ministerio de Economía, Industria y Comercio. Asimismo, una síntesis de este trabajo fue presentada en una ponencia durante el 'III Simposio 'To be or not to be'. El papel del diseño en la construcción de identidades", organizado por la Fundació Història del Disseny y llevado a cabo en el Museu del Disseny de Barcelona los días 12 y 13 de marzo de 2020, para esta ocasión bajo el título "Murcia, Huerta de Europa: Imagen, propaganda e identidad en la ephemera comercial de la primera mitad del siglo XX".
} 
denominación de origen de diversas empresas de varios sectores, principalmente agroalimentarias, y al mismo tiempo a su asimilación con esta región levantina gracias a sus hitos arquitectónicos, la huerta o sus tipos populares. Esta última premisa es la que abordaremos dentro de este estudio al contrastarlas con otras representaciones anteriores.

\section{PALABRAS CLAVE: Etiquetas, ephemera, Murcia, identidad, cromolitografías.}

\section{ABSTRACT}

One of the less treated sections of the visual representations of Murcia has been the comercial ephemera. For this reason, given its limited and fleeting use, it has often not been considerated as a valvable section in the history of art. But the truth is that the labels of canning factories, fruits, liquors and other establishments, from the last years of the 19th century based on the design spread the most significant identity elements of this territory throughout Spain and the rest the world. In the majority of cases, the advertising brand was based on prints and images of Murcian romantic costums that had already been consolidated during the 19th century for the social demand of this currens, in other cases they were adapted to the new aesthetic criteria of the 20th century. Finally, this way of advertising each product helped to panted the denomination of origin of various companies, mainly agry-food, and at the same time to assimilate it with this southeast region thanks to its architectural landmarks, the orchard or its popular types. This last premise is the one we will address within this study when contrasting them other previous representations.

KEYWORDS:
ephemera, Mubels,
chromolithography.

Desde los últimos años del siglo XIX, las imágenes diseñadas para etiquetas de comercios e industrias fueron, en la gran mayoría de casos, la carta de presentación del producto en los mercados nacionales e internaciones. Esta tipología de representaciones o estampas, plasmada sobre distintos soportes - papel esencialmente- (Ramos Pérez, 2002), además de captar la atención del público y dar a conocer el producto también sirvió como un singular medio de expresión en el que quedarían incorporados algunos conceptos identitarios de los territorios españoles, relacionados a su vez con los imaginarios colectivos nacionales e internacionales. En varios ejemplos de la ephemera comercial de Murcia que incorporamos en este estudio, analizaremos algunos diseños de etiquetas que muestran una composición que quedó atildada con ciertos elementos que volvieron a patentar los principales signos de identidad de esta región, casi siempre relacionados con su capital: la huerta, la barraca, la catedral, el río Segura, los tipos populares... A colación del término utilizado para designar a estas representaciones publicitarias y de propaganda, ephemera, Ramos Pérez (2002) establece en su estudio que se aplica a todo aquello que tiene una duración muy breve. Asimismo, John Lewis empleó por primera vez este vocablo en su obra Printed Ephemera (1962), para aglutinar e identificar a todas aquellas 
obras impresas sobre papel que eran producidas para un uso limitado y desechable, tales como las mencionadas etiquetas de productos agroalimentarios, envoltorios, almanaques, tarjetas y carteles publicitarios; al igual que felicitaciones, encabezados de facturas, folletos electorales, invitaciones de teatro y conciertos, etc.

En cualquier caso, según la opinión de Martínez Carrión (1999: 149-186), gran parte de las empresas murcianas llegaron a alcanzar cierta reputación dentro de los circuitos nacionales gracias a las diversas formas de envasar, envolver y etiquetar muchos de sus productos, así como por el diseño de la imagen que utilizaron para patentar su marca. Sin duda, un ejemplo de ello fue la industria del pimentón de Murcia, la cual comenzó a desdeñar la exportación a granel a otros países de Europa y América ya que el material en ocasiones era adulterado en el lugar de destino. Para evitar este inconveniente, a partir de la década de 1920, los exportadores españoles idearon diversas estrategias de marketing con las que intentaban consolidarse dentro de los mercados americanos. De esta manera aumentarían la competencia y calidad de su mercancía. Así fue como se comenzó a envasar el producto en envases más pequeños. En este contexto, las empresas pimentoneras enlataron el "oro rojo" murciano con sus respectivas marcas y etiquetas en botes metálicos con delicados diseños de vistas y tipos populares de esta provincia que, en la mayoría de los casos, estaban inspirados en otras estampas -grabados, cromolitografías o fotografías- del siglo XIX. A partir de estos cambios, la marca o diseño del embalaje pasó a convertirse en el símbolo de calidad de la empresa, al igual que pasaría a ser el referente visual primordial del territorio de origen.

En casi todas las etiquetas de las fábricas exportadoras de pimentón, conservas, frutas, licores y, también, establecimientos hoteleros que hemos añadido en este análisis la secuencia iconográfica es prácticamente idéntica. En ocasiones, la marca va acompañada de alguna vista urbana o elemento que ilustra y refuerza visualmente la propaganda de la empresa, que en la mayoría de casos, como advertimos, estaban basados en unos patrones que ya habían quedado establecidos anteriormente en las diferentes manifestaciones artísticas y literarias. Muchas de estas representaciones conformaron parte del imaginario visual colectivo que ya se tenía de Murcia en toda España y parte de Europa desde el siglo XIX, como fueron sus monumentos, paisaje, sociedad o tradiciones. En otras etiquetas, especialmente en las fábricas de destilados, se pretendía enaltecer el acervo cultural de la provincia por medio de sus personajes más notables como, por ejemplo, el afamado escultor murciano Francisco Salzillo y Alcaraz (1707-1783) y sus archiconocidos pasos de Semana Santa, o el pensador y político Diego de Saavedra Fajardo (1584-1648), autor de una importante obra literaria -entre otras- del Barroco español, Idea de un príncipe político cristiano: representada en cien empresas, dedicada al príncipe de las España nuestro señor (1643).

Para con los grandes hitos humanos de Murcia, como el mencionado Salzillo, recordemos que fue a partir del siglo XIX cuando la figura de este escultor y sus obras cobraron importancia dentro de la literatura que se comenzó a desarrollar alrededor del artista; aunque en muchos casos estuviese un tanto idealizada en base a leyendas gestadas bajo los preceptos románticos. Al igual que otros personajes como José Moñino y Redondo, conde de Floridablanca y ministro de Carlos III, Francisco Salzillo alcanzó gran fama y reputación nacional, pasando a formar parte de los personajes ilustres que esta 
provincia levantina aportaba a la cultura de España ${ }^{2}$. A merced de estos asuntos, desde mediados del ochocientos los pasos que este artista realizó para la Cofradía de Jesús de Murcia, que desfilan en la procesión matutina del Viernes Santo, también fueron aceptados y apropiados como parte de las marcas y publicidades fabriles y de la identidad regional mediante fotografías, postales, etiquetas, carteles, etc. También Saavedra Fajardo fue redescubierto durante el siglo XIX, quien, al igual que Francisco Salzillo, ganó en fama durante esta centuria, pues desde ese momento las élites murcianas comenzaron a homenajear y biografiar las vidas de sus principales figuras como una fórmula de patentar su prestigioso pasado histórico, cultural y artístico. Sin duda este asunto tiene que ver mucho con el pensamiento y aptitud del romántico, pues durante este heterogéneo periodo florecieron los festejos conmemorativos que laureaban las efemérides y centenarios de los nacimientos o fallecimientos de los personajes más señeros de la provincia Murcia (Hernández Vicente, 2018). Desde la era isabelina este asunto fue algo que se repitió en diversas ciudades y provincias españolas durante todo el siglo.

Las principales actividades comerciales de esta región del sureste español mantuvieron prácticamente la misma fisionomía económica que en el siglo XVIII (Pérez Picazo, 1980: 40), pues la industrialización de Murcia, aunque lenta, finalmente comenzó a ser productiva desde finales del siglo XIX. Ya en este periodo se constatan algunas fábricas, agroalimentarias principalmente, que exportaban sus productos por todos los circuitos de España y los mercados internacionales, especialmente el francés (Martínez Carrión, 2002: 342). Gracias a la versatilidad de estos negocios, las empresas litográficas y sus diseñadores encontraron un medio de expresión con el que potenciar los grandes referentes territoriales. Al mismo tiempo, la imagen publicitaria también comenzó a convertirse de facto en la transmisora de esas ideas regionalistas dentro de los diarios y revistas ilustradas de la época con el fin de atraer y ganar la confianza del cliente (Ramos Frendo, 2008: 121). En ese proceso de modernización de la industria murciana y el coincidente desarrollo de la prensa ilustrada fue cuando, a posteriori, se fomentó la marca "Murcia, huerta de Europa", que terminaría por patentarse durante la década de los cincuenta del siglo pasado dentro los preceptos políticos del Régimen franquista. No es casualidad que desde finales del siglo XIX ya existía una reputada conciencia sobre la excelencia de la huerta murciana a nivel nacional. En la Exposición Regional de Logroño, celebrada en 1897, el redactor de un periódico murciano, presente en aquella ciudad durante el evento, se quejaba de que Murcia no estuviese presente en tal exposición, pues "los tres paisanos nos hemos lamentado de no ver en esta Exposición producto alguno de nuestra rica y exhuberante[sic] huerta que, como es sabido, goza de fama universal. Nuestro pimiento molido en toda su pureza, nuestras frutas [...]" (El Diario de Murcia, 15/10/1897: 1). Lo cierto es que la primera referencia al término "Huerta de Europa", como ya hemos atestiguado, es relativamente reciente. No es hasta finales del año 1959 cuando aparece exactamente tal término bajo un titular del periódico Línea (12/09/1959, 12), en el cual se aludía a que "Murcia debe ser la huerta de Europa".

Durante ese lapso de tiempo aparecieron diversos argumentos propagandísticos

\footnotetext{
${ }^{2}$ A modo de ejemplo, véanse los trabajos de Cristina Torres-Fontes Suárez, "Francisco Salzillo o el pensamiento firmado", en Salzillo, testigo de un siglo, coord. Cristóbal Belda Navarro (Murcia: Comunidad Autónoma de la Región de Murcia, 2007), 347-359; Ignacio José García Zapata, "Francisco Salzillo en la Prensa Periódica del siglo XIX”, en Iberian, n. ${ }^{\circ} 8$ (2013): 5-17.
} 
dentro de la prensa murciana con una intencionalidad clara y contundente sobre el futuro de la industria agroalimentaria de esta región: "Murcia puede ser la gran reserva nacional. La feracidad de su suelo permite definirla como futura huerta de Europa" (Hoja del Lunes, 21/09/1959: 1). Estas propuestas, avaladas por el prestigioso catedrático de Teoría de Económica de la Facultad Ciencias Económicas de la Universidad Central, Manuel de Torres Martínez, exponían que la explotación agraria de la provincia de Murcia estabilizaría la economía española, puesto que "[...] el afianzamiento y desarrollo de la economía española, dentro de las directrices actuales, sólo puede lograrse cuando, empleando una imagen gráfica, Murcia se transforme en la Huerta de Europa" (Hoja del Lunes, 21/09/1959: 7). Por tanto, en este nuevo cuño también podemos observar otra nueva seña de identidad, la cual, junto a la ephemera comercial, pretendía acrisolar a este territorio como uno de los principales referentes exportadores en Europa, y también dentro de España, en base a una de sus singularidades: su fértil y productiva huerta.

\section{LAS FÁBRICAS DE PIMENTÓN}

Como dijimos, desde el siglo XIX, gracias a los adelantos industriales y científicos, las fábricas pimentoneras fueron uno de los principales sustentos económicos de los campesinos, fabricantes y exportadores de las huertas de Murcia y Orihuela. Aunque en realidad el peso de la producción recayó en las empresas murcianas, establecidas en dos pedanías que han quedado como referente en este sector: Espinardo ${ }^{3}$ y Cabezo de Torres (Martínez Carrión, 1999: 157). Ya señalamos que el pimentón murciano se distribuyó en envases de metal en los que se plasmaba un diseño que, casi siempre, hacía alusión a un elemento identificador de la provincia. En esta categoría, la fábrica de pimentón de Fulgencio Alemán, de Espinardo, fue una de las tantas que acudió a los arquetipos murcianos para patentar su producto, en este caso con la marca "El Huertano" (FIGURA 1). El diseño del bote estaba basado en un recurso harto utilizado durante toda la centuria decimonónica: el tipo popular vestido con la indumentaria regional. En este caso, el tipo masculino aparece en el centro del pseudo-escudo de la ciudad de Murcia, suprimiendo el corazón del Alfonso X el Sabio, vestido a la usanza de los huertanos de esta provincia y de otras provincias levantinas: zaragüelles, camisa, chaleco, medias, esparteñas, manta y montera. Sin duda, un diseño harto recurrente para patentar y prestigiar el origen del fabricante. En esta misma línea, la marca "Pimentón Murciano" también optó por identificar y relacionar su producto con la huerta de Murcia mediante el traje regional. Sin embargo, en este caso el diseñador incorporó cuatro elementos identitarios en la misma etiqueta: una mujer vestida con el traje regional sentada en la puerta de una barraca y entre una frondosa huerta, y al fondo la torre de la catedral. En el anverso de la lata la torre de la catedral asoma entre una frondosa huerta de limoneros, naranjos y palmeras. Este tipo de estampas fueron muy fecundas durante el periodo de la Restauración (1874-1931) presentadas en cromolitografías coloreadas, grabados o fotografías, como las del francés Jean Laurent o el murciano Juan Almagro.

Como ya aseguramos, la industria pimentonera murciana mantuvo la primacía en

\footnotetext{
3 Sobre la industria pimentonera de Murcia, también véase a modo de ejemplo a José Antonio Marín Mateos, "Espinardo y el pimentón 1848-1960", en Cangilón, n. 35 (2016): 19-58; Ricardo Montes Bernárdez, "Historia del pimentón en Murcia 1730-1945”, en Cangilón, n. 35 (2016): 3-18.
} 
el mercado nacional, también en el internacional, hasta la mitad del siglo XX. Por este asunto es que nos encontraremos con casos singulares en los que el diseño estuvo basado en otros elementos identitarios relacionados con los lugares de destino del producto. Uno de estos ejemplos se verifica en la etiqueta del exportador Manuel Planes García, de Espinardo, quien tituló la marca de su pimentón como "El Pasiego". De este modo, los empresarios murcianos también establecían un vínculo con las provincias destinatarias al homenajear con un tipo popular del Valle del Pas (Cantabria) a aquellas zonas del norte de España, ya que estas regiones fueron uno de los principales destinos del mercado interior de esta especia murciana para la elaboración de embutidos y guisos (Martínez Carrión, 1999: 159). Asimismo, por subrayar otro modelo, la fábrica de José Flores Noguera, nuevamente de Espinardo, optó por ilustrar sus envases con el diseño de un Santiago Matamoros, muy en consonancia con la tradición devocional de estos puntos de la Península. No son los únicos casos, pues el Museo de la Ciudad de Murcia custodia una pequeña colección de 40 latas de diferentes empresas en las que se aprecian estas excepciones en los diseños de las etiquetas, como también se repite en la marca de pimentón "El Gaitero" de la fábrica de José Antonio Sánchez Laorden, establecida en Santomera. Como dato curioso, debemos reseñar que muchos de estos envases, esencialmente los de gran tamaño, fueron utilizados a modo de instrumento de percusión -como un pandero- para el acompañamiento de los cantes y bailes populares de algunas regiones del norte español: Galicia, Asturias, León, Cantabria, etc. A día de hoy, muchos grupos folclóricos de estos territorios aún mantienen estas latas de pimentón murciano para hacer música popular, perviviendo en la marca o el diseño las imágenes que hemos reseñado.

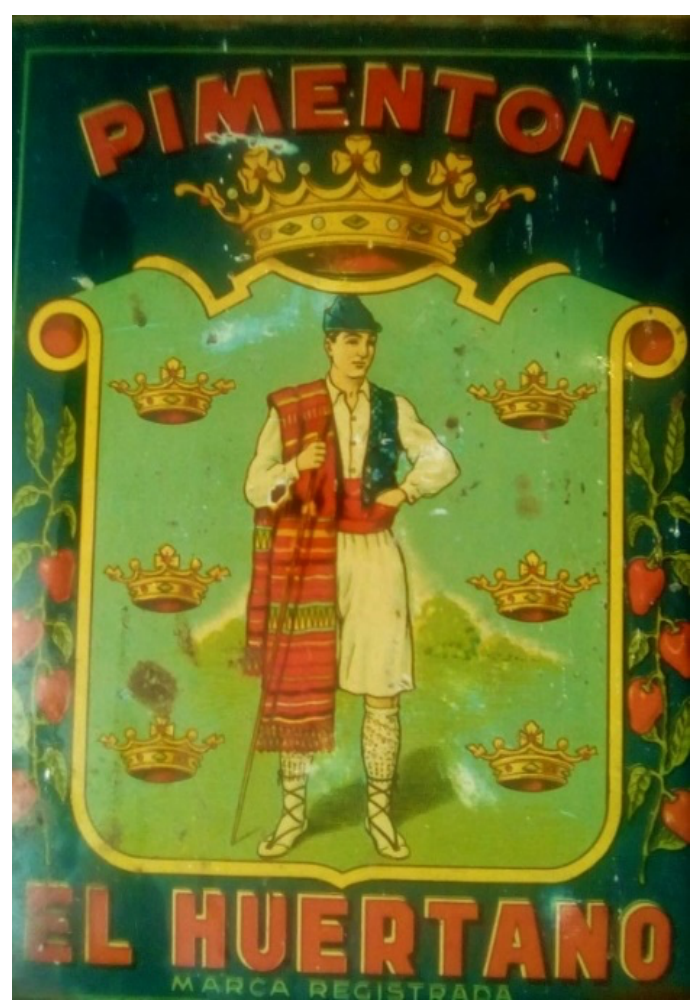

FIGURA 1: CROMOLITOGRAFÍA SOBRE METAL. "PIMENTÓN EL HUERTANO", SEGUNDA MITAD SIGLO XX. 

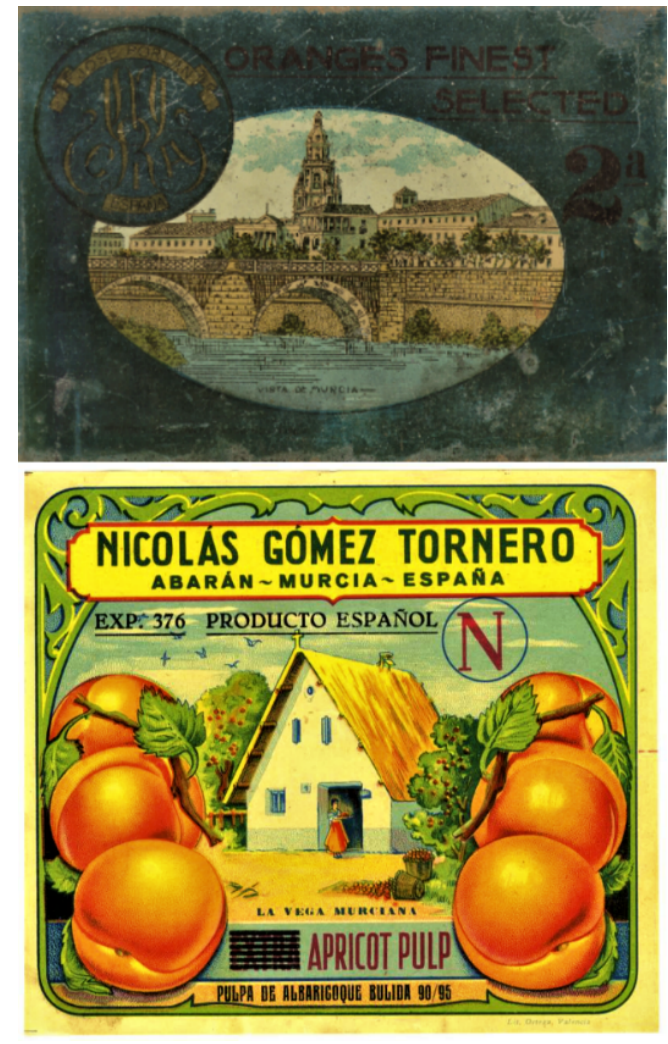

FIGURA 2: (Superior) CROMOLITOGRAFÍA SOBRE METAL. "ORANGES FINEST SELECT", ÚLTIMO TERCIO SIGLO XIX. (Inferior) CROMOLITOGRAFÍA SOBRE PAPEL. "LA VEGA MURCIANA", SEGUNDO TERCIO SIGLO XX. ARCHIVO DE LA REGIÓN DE MURCIA.

\section{LAS FÁBRICAS DE CONSERVAS Y FRUTAS}

No alberga ninguna duda que una de las imágenes más repetidas en los diseños de la ephemera comercial de Murcia fue la vista del río Segura, desde lado oeste con la torre de la catedral de fondo, o la desde el este con el Hotel Victoria y el Malecón. En algunos ejemplos que añadimos a este trabajo podremos constatar que esta estampa pasó a ser el sello distintivo y más definitorio de la ciudad. Recordemos, además, que una de las primeras fotografías en la que aparece esta vista urbana fue la realizada por el fotógrafo galés Charles Clifford en 1862 durante el viaje que Isabel II realizó a Murcia en octubre de aquel año. Esta vista se publicó en el álbum fotográfico que acompañó a la crónica del viaje real (Cos-Gayon, 1863).

Posteriormente, otros fotógrafos como el francés Jean Laurent y también grabadores o ilustradores volvieron a utilizar este mismo paisaje como paradigma de la capital del Segura. En estas representaciones siempre aparecían algunos de los monumentos más emblemáticos y representados de esta ciudad desde los inicios del siglo XIX: el Puente Viejo, la catedral, el Ayuntamiento, el Palacio Episcopal o los desparecidos edificios del hospital de San Juan de Dios y de la Inquisición ${ }^{4}$. Todas estas estampas quedarán como paradigma visual de Murcia en pinturas, grabados, fotografías, cromolitografías e incluso en el cine hasta prácticamente la actualidad.

Uno de los prístinos ejemplos de la ephemera murciana con las características reseñadas anteriormente lo encontramos en la chapa litografiada de la fábrica de naranjas de José Porlán (FIGURA 2). Este diseño gráfico es prácticamente idéntico a otro posterior, el de la etiqueta en papel de la fábrica conservera de Pedro Cascales, de Alcantarilla, pues en ambas empresas los diseñadores gráficos emplearon el mismo dibujo para patentar y fundamentar la marca murciana. Este diseño se corresponde con la vista general desde sur de la ciudad Murcia que hemos citado en el epígrafe previo realizada por Clifford. Todos estos edificios pasaron a ser los hitos arquitectónicos más

\footnotetext{
${ }^{4}$ El solar del edificio de la Inquisición lo ocuparía a finales del siglo XIX el Hotel Universal, que a principios del siglo XX pasaría a ser renombrado como Reina Victoria, en honor a la Reina Victoria Eugenia de Battenberg. Posteriormente, durante el segundo periodo republicano, únicamente se le denominó como Hotel Victoria.
} 
notables de la ciudad. También, la etiqueta de la fábrica de conservas de Nicolás Gómez Tornero (FIGURA 2), de Abarán, aun estando fuera del área metropolitana de la ciudad de Murcia, muestra otro elemento idiosincrásico de este territorio levantino: la barraca, construcción tradicional de las gentes que habitaban la huerta de Murcia, como también lo había sido en la huerta de Valencia. En el municipio de Abarán, ubicado en la Vega Alta del Segura, inserto en el exuberante paisaje del Valle de Ricote, también ha existido una gran tradición conservera desde mediados del siglo pasado.

No menos importante es la original etiqueta de la fábrica exportadora de naranjas de José Manuel Meseguer (FIGURA 3), de Alquerías, con un curioso y singular diseño del pintor cartagenero Vicente Ros (1887-1976). Esta etiqueta, sin lugar a dudas, es una de las más novedosas en cuanto al diseño que este artista, bohemio y vanguardista, dibujó para esta empresa murciana (Páez Burruezo, 2012: 187). Aunque en su biografía artística no aparece ninguna reseña de su aportación a las artes gráficas, este ejemplo nos atestigua su contribución a este género pictórico. En este caso Ros acudió a un diseño para la marca de la casa, "The Noble-Man", que alude a uno de los grandes y quijotescos tópicos del pueblo español creado durante el Romanticismo: su heroico espíritu caballeresco, que también sirvió como caldo de cultivo para patentar las singularidades de los españoles en general.

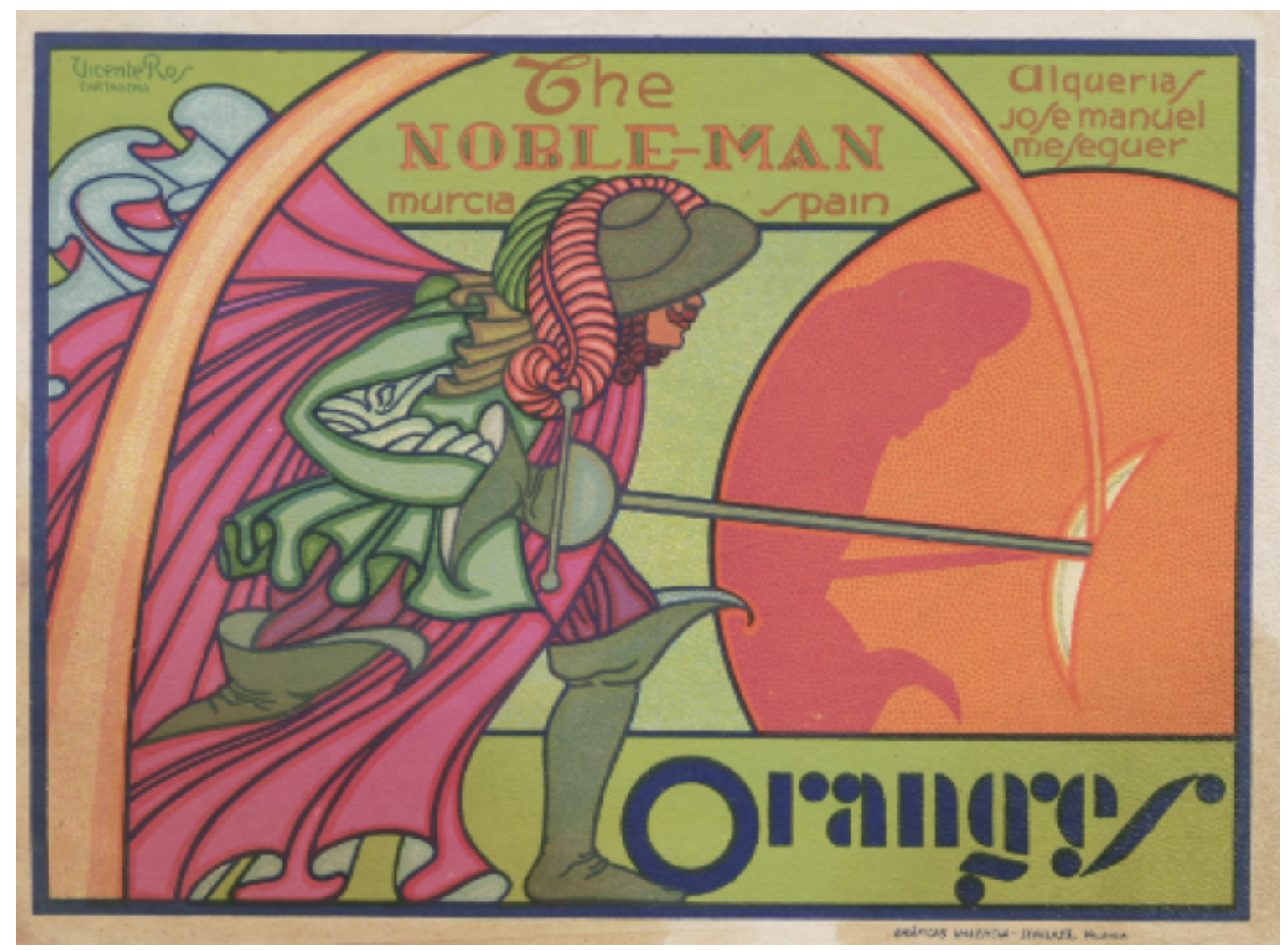

FIGURA 3: CROMOLITOGRAFÍA SOBRE PAPEL. DISEÑO DE VICENTE ROS. "ORANGES. THE NOBLEMAN”, SEGUNDO TERCIO SIGLO XX. ARCHIVO DE LA REGIÓN DE MURCIA. 


\section{ETIQUETAS DE HOTELES}

En las tarjetas de visita de los hoteles Internacional, Madrid, Victoria y Avenida vuelven a aparecer los mismos hitos arquitectónicos que reseñamos anteriormente para las etiquetas de empresas agroalimentarias. En ocasiones aparecen individualizados, como es el caso del Hotel Avenida, donde la torre de la catedral protagoniza el diseño de la tarjeta, o la del Hotel Madrid (FIGURA 4) que utiliza la misma imagen, pero con palmeras. A estas tres tarjetas, además, se les ha añadido otro protagonista de la identidad visual y cultural de Murcia que ya aparecía en las etiquetas de pimentón: el tipo popular. Lo cierto es que todos estos asuntos, dentro de los imaginarios europeos decimonónicos, expresaron una sensibilidad especial que evocaban aquellos mitos románticos sobre el sur peninsular, de mundos exóticos y orientales, de tipos rurales vestidos con "pintorescos ropajes" y de fecundas huertas, que quedaron cristalizados en la literatura de viajes 5 . Pero, en paralelo, también fue fecunda la pintura, fotografía y litografía costumbrista de tipos y escenas populares que floreció en la España de la Restauración y que fecundó mucho más el tópico de estos territorios.

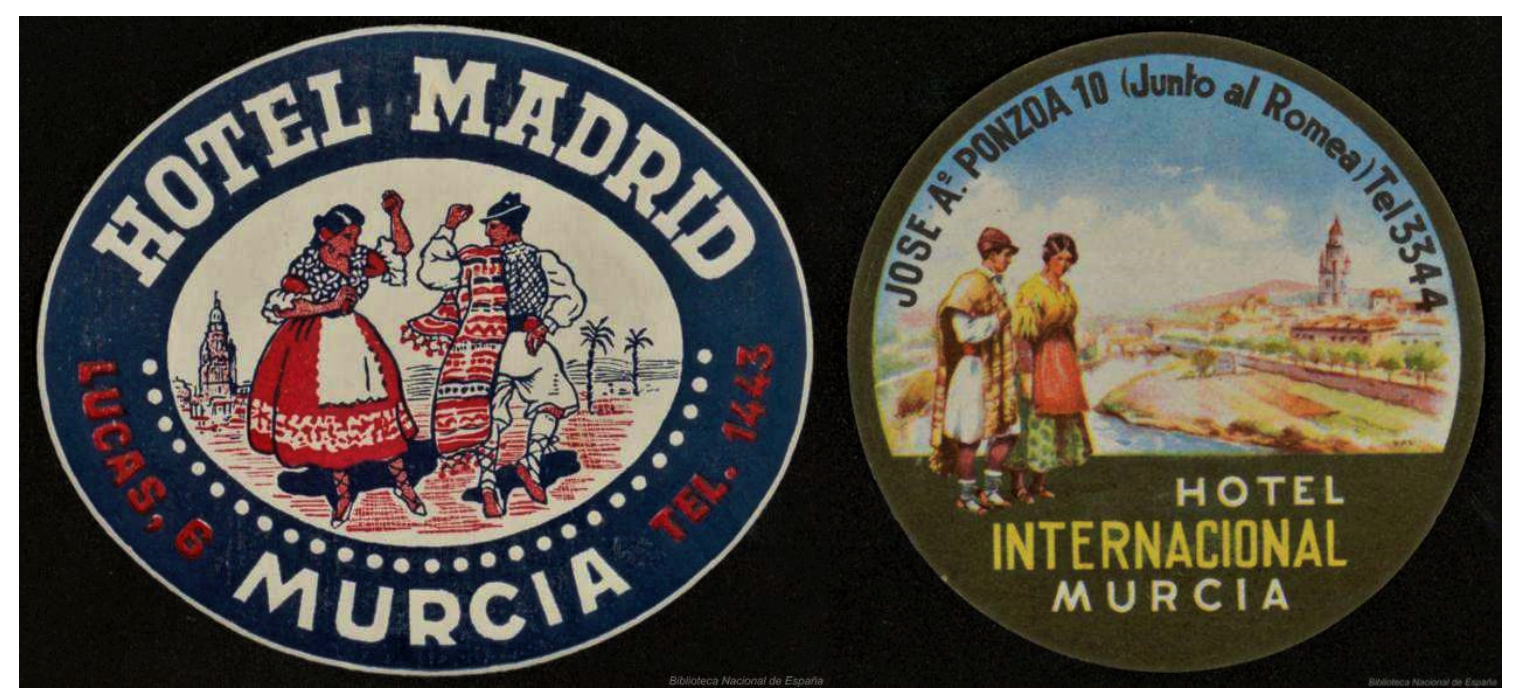

FIGURA 4: (Izquierda) CROMOLITOGRAFÍA SOBRE PAPEL. "HOTEL MADRID", SEGUNDO TERCIO SIGLO XX. (Derecha) CROMOLITOGRAFÍA SOBRE PAPEL. "HOTEL INTERNACIONAL", SEGUNDO TERCIO SIGLO XX. BIBLIOTECA NACIONAL DE ESPAÑA.

Asimismo, es notable el diseño de la etiqueta del prestigioso Hotel Victoria (FIGURA 5), la cual viene firmada por el pintor murciano Luis Garay (1893-1956), uno de los pioneros en las artes gráficas, quien comenzó su andadura artística en diseños para las industrias de Murcia. Garay, como señala Páez Burruezo (2012: 201), “[...] supo reflejar desde su pintura, desde sus escritos, con la sensibilidad de creador, una época de Murcia". Pues en esa personal sensibilidad artística, plasma los aspectos más

\footnotetext{
${ }^{5}$ Sobre la literatura de viajes de Murcia, véase a Cristina Torres-Fontes Suárez, Viajes de extranjeros por el Reino de Murcia (Murcia: Asamblea Regional y Real Academia de Alfonso X el Sabio, 1996).
} 
sobresalientes de su ciudad al dar una nueva luz a enfoques estilísticos y conceptuales de las gráficas comerciales de los años treinta del siglo XX con esta pareja de huertanos. Pero en este caso, como también ocurre en la tarjeta del Hotel Madrid, a diferencia de los clásicos tipos femeninos y masculinos que ya se habían prodigado en postales y estampas durante la centuria anterior, aparecen en movimiento y ejecutando un baile popular.

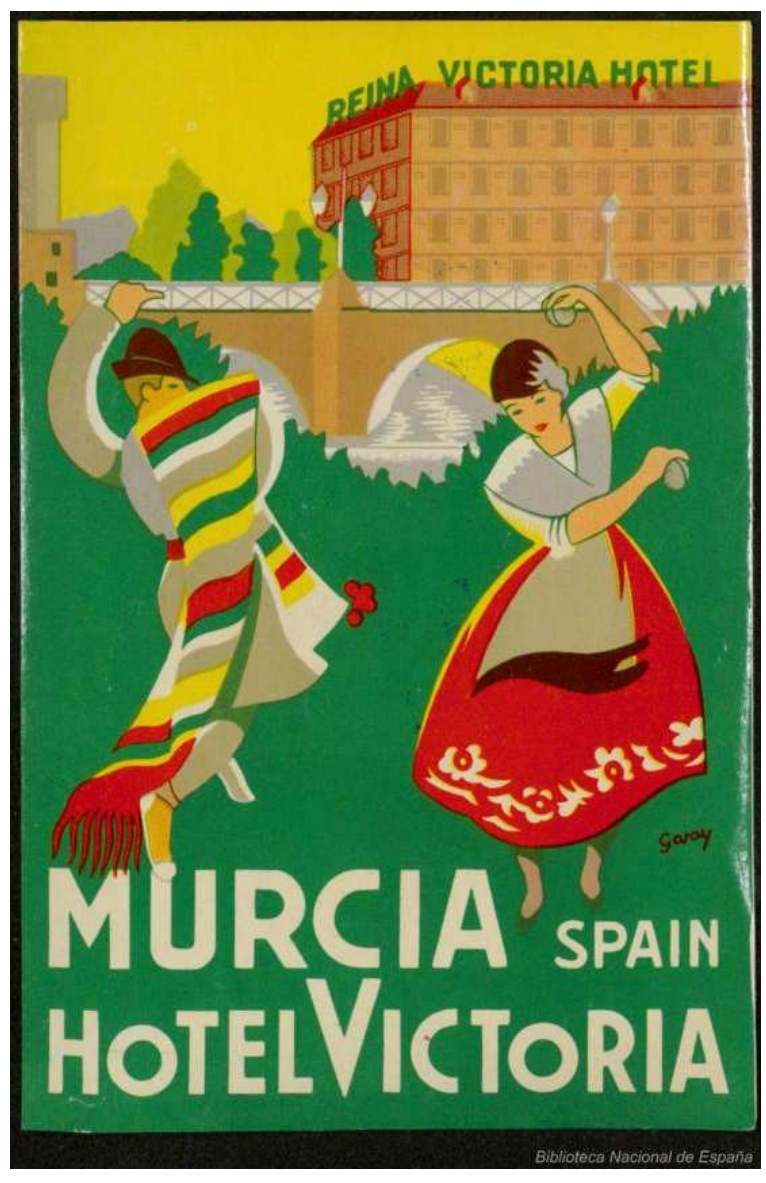

FIGURA 5: CROMOLITOGRAFÍA SOBRE PAPEL. DISEÑO DE LUIS GARAY. "HOTEL VICTORIA", SEGUNDO TERCIO SIGLO XX. BIBLIOTECA NACIONAL DE ESPAÑA.
Podemos atestiguar que hasta ese momento estos dos diseños supusieron una novedad al añadirle otro tratamiento a los tipos populares, pues generalmente los personajes que estaban insertos en algún paisaje urbano o de huerta se les representaba con un carácter más hieratismo. Como es el caso de la pareja de huertanos de la tarjeta publicitaria del Hotel Internacional (FIGURA 4), más clásicos y en consonancia con las representaciones de cariz románticocostumbrista del siglo XIX y que, además, vuelve a repetir la misma vista de la ciudad que aludíamos anteriormente. Por cierto, según consta en la Biblioteca Digital Hispánica -en su sección de "Etiquetas de hoteles de Murcia-, esta última tarjeta también viene rubricada por otro ilustrador, Val, y queda reseñado el taller de realización, Gráfica Manén de Barcelona.

El Hotel Victoria fue desde su creación uno de los más prestigiosos y visitados de Murcia. Por su extraordinaria ubicación junto al río Segura, el Plano de San Francisco, el Arenal y la Glorieta de España pasó a ser el gran escaparate de la ciudad para los visitantes que llegaban desde otros puntos de España o Europa. En una de las postales publicitarias de este inmueble -por cierto, con una publicidad con miras internacionales ya que el texto está en francés, al igual que sucedía con algunas etiquetas de las fábricas de conservas- se publicitaba como "Victoria Hotel, ler ordre-4 facades. Des ses balcons on domine les merveilleux et tant renommés Jardins de Murcie" (FIGURA 6). Este reclamo, "los famosos Jardines de Murcia", sin duda, aludía a la imagen que el país vecino ya tenía consolidada en su imaginario colectivo de esta región, y más concreto desde miras cinematográficas. 


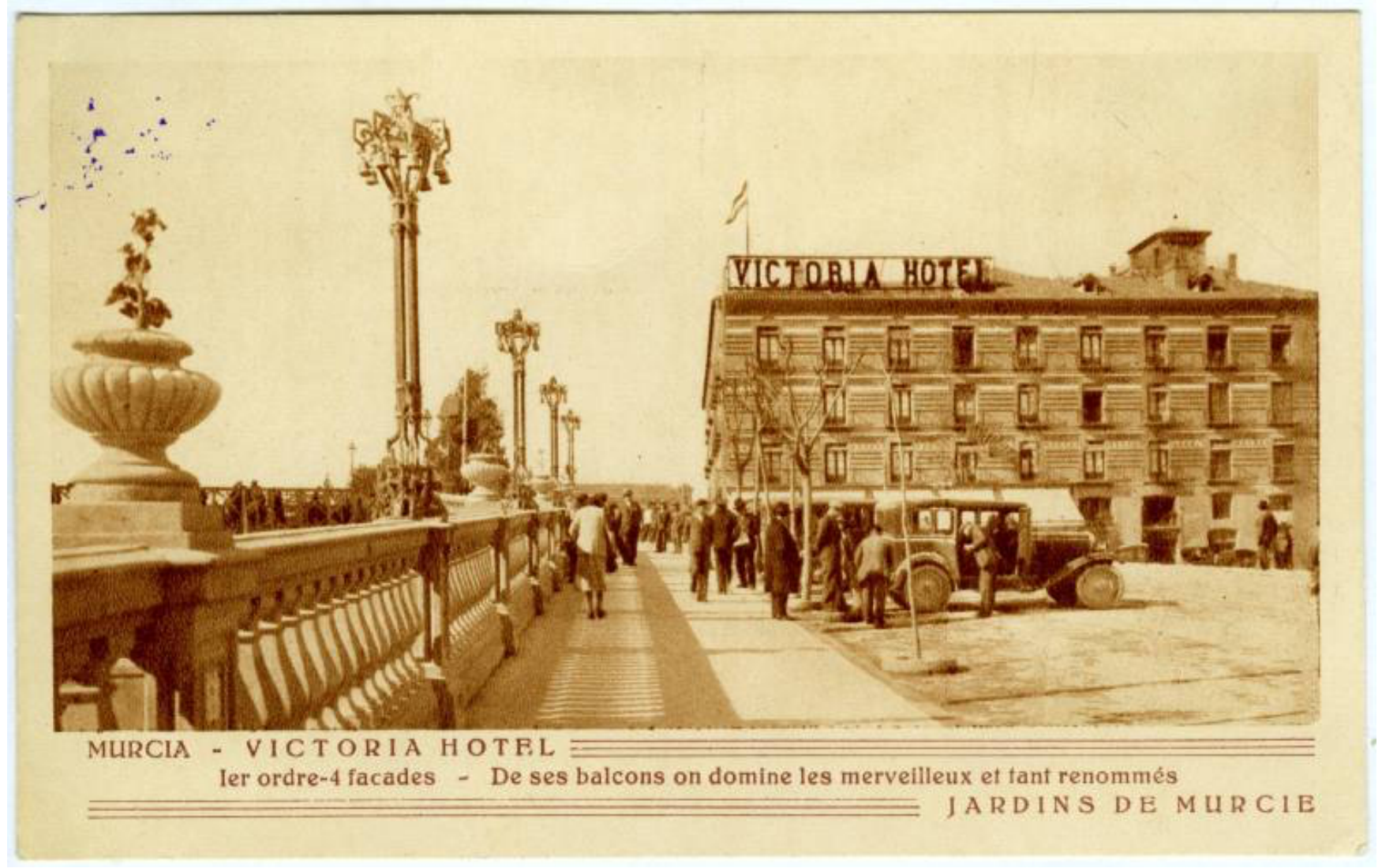

FIGURA 6: FOTOGRAFÍA SOBRE PAPEL. "HOTEL VICTORIA", SEGUNDO TERCIO SIGLO XX. ARCHIVO DE LA REGIÓN DE MURCIA.

Estas imágenes simbólicas terminaron de fraguarse a principios del siglo XX gracias al film Aux Jardins de Murcie, basado en un drama rural de la obra teatral María del Carmen (1896) de Felíu y Codina, que ya había sido adaptada y traducida al francés. En 1923 la obra pasó a la gran pantalla de mano de la productora francesa Les films Mercaton, versión realizada por Carlos de Battle y Antoinet Lavergne bajo el título Aux Jardins de Murcie. La primera versión muda fue dirigida por Louis Mercaton y René Hervin y, doce años más tarde, tras el gran éxito de esta primera versión, se realizó una segunda ya en cine sonoro dirigida por Max Joly y Marcel Gras, la cual se estrenó el 27 de noviembre de 1936 en el cine L'Ermitage de París. El rodaje de esta última versión se realizó en Murcia durante el otoño de 1935 (Cánovas Belchí, 2016: 303-324). Si nos remontamos un siglo atrás encontraremos el primer indicio del interés del pueblo francés por España. Tras la invasión Napoleónica, Francia fue una de las primeras naciones europeas -junto con Inglaterra- que redescubrió la Península al resto de países del continente, al cambiar aquella visión un tanto perniciosa de siglos pasados hacia una percepción positiva, aunque de manera muy superficial. 


\section{DESTILERÍAS Y AGUARDIENTES}

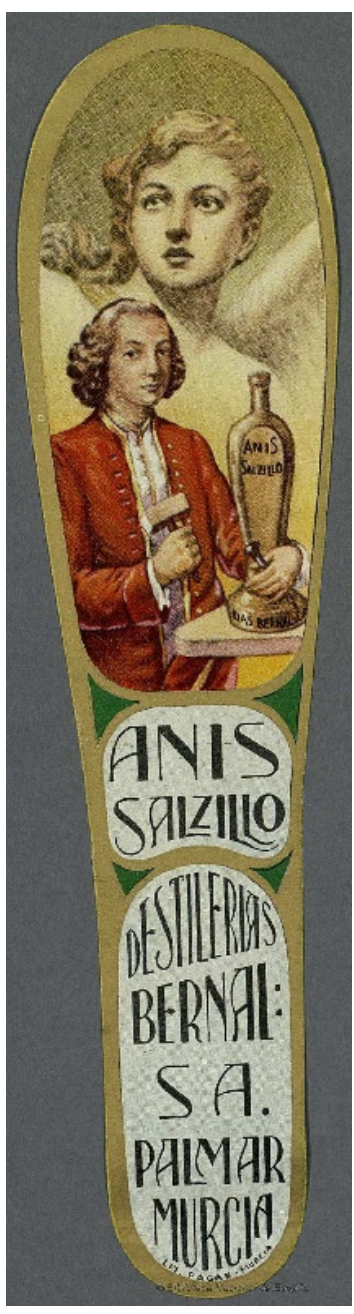

FIGURA 7:

CROMOLITOGRAFÍA SOBRE PAPEL. LITOGRAFÍAS PAGÁN (MURCIA. "ANÍS SALZILLO", SEGUNDO TERCIO SIGLO XX. BIBLIOTECA NACIONAL DE ESPAÑA.

En el espectro de la ephemera comercial de Murcia que venimos tratando también se practicó con ahínco el diseño de las marcas de bebidas, las cuales en diversos casos hacían mención a las glorias murcianas en sus denominaciones. Dos de las más prestigiosas fábricas de destilados de Murcia de mediados del siglo XX, Destilerías Bernal, de El Palmar, y Destilerías Barceló, de Algezares, dieron nombre a sus licores basándose en ilustres personajes de la cultura de esta región. La primera fábrica exportó la marca "Anís Salzillo" (FIGURA 7) con un diseño gráfico en el que aparecía el retrato del laureado escultor murciano como artífice de la original y sinuosa botella de este licor. Sin duda, el diseñador de esta etiqueta se tuvo que inspirar en el retrato idealizado que Juan Albacete realizó a principios del siglo XIX para la Real Sociedad Económica de Amigos del País de Murcia, actualmente conservado en el Museo Salzillo de esa ciudad. En la etiqueta de la botella aparece la marca de Litografía Pagán, de Murcia. Detrás del insigne escultor aparece una de sus obras más emblemáticas, la cual ha pasado a ser un icono de la Semana Santa de Murcia: el ángel del paso de La Oración en el huerto, obra realizada en 1754. De igual manera, esta empresa recurrió a los mismos tópicos que las fábricas de conservas y pimentón para otro producto, pues utilizó la indumentaria regional como diseño de la marca "Anís la Murciana", en este caso con una etiqueta de un tipo popular femenino ataviado con el característico ya "típico" traje de lentejuelas.

Sobre la indumentaria representada en este modelo de ephemera, en la que aparecen los trajes regionales españoles de mediados del siglo XX, tenemos que advertir que los tipos, aun teniendo su génesis en las colecciones de estampas y grabados de finales del siglo XVIII y todo el siglo XIX, visten un indumento que ya estaba totalmente desvirtuado $\mathrm{y}$ adaptado a los valores y exigencias que se le comenzó a dar durante el periodo franquista. Para este asunto debemos traer a colación las estampas de tipos populares de Juan de la Cruz Cano y Olmedilla, Juan Carrafa y José Ribelles Helip, entre otros. En esa "reconstrucción de la Patria" no solo entraron en juego los valores materiales, sino también había que recuperar un repertorio cultural y patrimonial acorde con el nuevo sistema político y que, a su vez, enlazara con los principios previos a la Segunda República. Por tales hechos, las indumentarias tradicionales de las diferentes provincias pasaron a conformar parte las bases identitarias de la "Nueva España" de mediados de siglo (Ortiz García, 2012: 1), por lo que la propia vestimenta popular comenzó a sublimarse a modo de identidad de una determinada región.

Volviendo a las etiquetas de licores, el empresario José Barceló Alemán también 
elaboró un brandy con el nombre del murciano más internacional de la primera mitad del siglo XVII, el diplomático y escritor Saavedra Fajardo, quien nació trescientos cincuenta años antes en el mismo pueblo donde se ubicó esta fábrica de licores, por lo que, obviamente, el empresario algezareño recurrió al nombre de este eximio personaje para promocionar su marca; como vemos, siempre conservando el vínculo con el territorio. Al igual que sucedía con el retrato de Francisco Salzillo, el ilustrador de la etiqueta se tuvo que inspirar en alguno de los grabados de este escritor que ya circulaban desde finales del siglo XVIII, como el realizado por Fernando Selma en 1791 -actualmente ubicado en la Biblioteca Nacional de España-. Además, en las tarjetas publicitarias que esta fábrica de licores y jabones utilizó para promocionar la marca empresarial, al igual como hizo Destilerías Bernal con el anís, también se sirvió de Salzillo como singular recurso al estampar en postales propagandísticas sus pasos del Viernes Santo como emblema y vínculo territorial como, por ejemplo, el ya representado paso de La Oración en el huerto.

Siguiendo la estela de la fábrica de licores de Barceló, pero muy acordes con los diseños de las fábricas conserveras, en ciertos casos otras casas de destilados y aguardientes murcianas también etiquetaron sus productos con diseños de tipos vestidos a la usanza tradicional, pero que al mismo tiempo asociaban la marca del artículo al gentilicio de origen. Sirva a modo de ejemplo el citado "Anís la Murciana" de Destilerías Bernal, el "Anisete Algezareña" de Destilerías Alemán, de Algezares, o "Anís de la Cartagenera" de Destilerías José A. Bernal, de Cartagena. En los dos últimos ejemplos también aparecen dos tipos femeninos vestidos con el indumento popular murciano, ya adaptado a la estética de mediados del siglo XX.

Casos de marcas de licores con diseños de etiquetas con diversos tipos populares de otros territorios encontramos prácticamente en todo el panorama nacional, aunque hubo un foco muy concreto que sí que acudió continuadamente a estas representaciones costumbristas: Andalucía. En este caso, la gran cantidad de fábricas de destilados y aguardientes de esta región, durante las últimas décadas del siglo XIX y principios de la siguiente centuria, optaron por ilustrar las etiquetas de manzanillas, moscateles o amontillados con estampas de majas, majos, toreros y manolas entre pintorescas escenas de ferias y bailes de flamenco. Finalmente, y como paradigma comparativo al sector fabril murciano, la especialidad vínica de este territorio pasó a conformar su identidad culturar mediante el "Marco de Jerez", adoptando así la denominación genérica de vinos de esta zona. De este modo, algunos productos como los mencionados vinos jerezanos y los ejemplos pimentoneros y conserveros murcianos alcanzaron sobre otros una diferenciación por medido de la calidad y la identificación con un territorio concreto. Además de los reseñados vinos de Jerez - también los de Málaga-, los aceites de Jaén, los jamones de Jabugo o las fresas de Huelva tipificaron la identidad de su lugar de origen (Martínez Carrión, 1999: 156).

Por resaltar algunos ejemplos de etiquetas de estos vinos, pues guardan relación con el tema que tratamos, vemos oportuno citar a: Gutiérrez Hermanos y sus marcas de "Pepe Hillo Manzanilla de Sanlúcar" y "La Espansiva[sic] Manzanilla de Sanlúcar" (FIGURA 8), o la de C. del Pino y Cía. con su jerez “i¡Viva Sevilla!!”. Por cierto, muchos de los diseños para las etiquetas de estas fábricas andaluzas estaban realizados en la prestigiosa Imprenta y Litografía de Fausto Muñoz, de Málaga ${ }^{6}$. Fausto Muñoz, además,

\footnotetext{
${ }^{6}$ Sobre este litógrafo y pintor malagueño, véase a Eva María Ramos Frendo, "Fausto Muñoz Madueño:
} 
nos sirve para ejemplificar aquellos diseños de etiquetas que, en ocasiones, vienen sin firma de un pintor y dibujante, pues este litógrafo malagueño, por su formación, era el encargado de realizar los dibujos que posteriormente servían para plasmarlos en la plancha. También hemos comprobado que en otras empresas litográficas el dibujo estaba realizado por algún artista externo o que trabaja para estas. Como hemos observado, en la gran mayoría de ejemplos murcianos que hemos citado no aparece ninguna rúbrica. En su defecto, como es el caso del Anís Salzillo, sí que viene impresa el litógrafo, entendiendo de este modo que el diseño y dibujo corrió a cuenta de esa empresa.
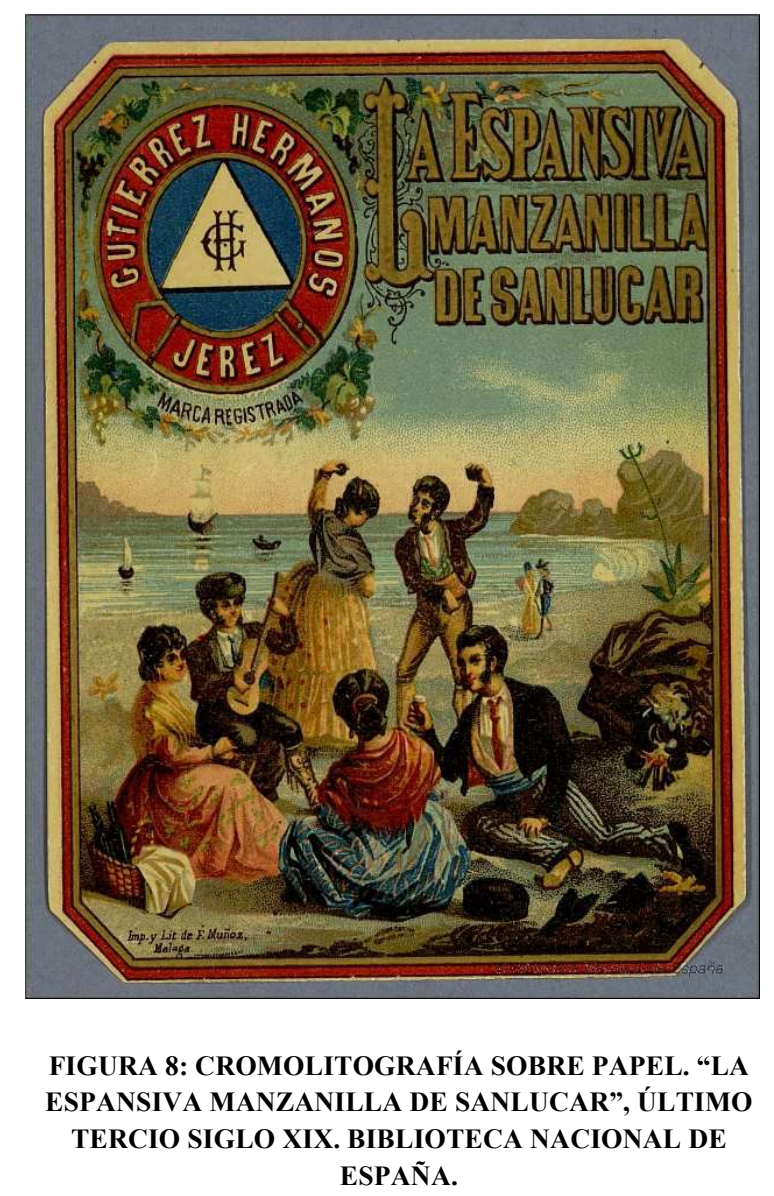

Además, desde los primeros años del siglo XX fue una práctica habitual en los diseños gráficos de las marcas comerciales de diferentes puntos de España la utilización de imágenes con cierto cariz regionalista. De este modo, y como acabamos de comprobar en el caso murciano o el andaluz, el producto quedaba identificado a primera vista gracias a estos patrones icónicos: trajes regionales, monumentos, artistas, escritores, escenas costumbristas, etc.

Podemos seguir enumerando diversos ejemplos de diferentes puntos de España y de diferentes géneros de productos, como fue el caso de las fábricas de perfumes o jabones. Varias etiquetas de esta tipología de ephemera quedaron recogidas en la exposición "El arte de la belleza", organizada por la Biblioteca Nacional de España desde

litógrafo malagueño", en Isla de Arriarán: Revista Cultural Cientifica, n. ${ }^{2} 20$ (2002): 171-191. 
el 15 de marzo a 5 de junio de 2011 (Ramos Pérez, 2011). En esta interesante y genuina muestra deberíamos destacar los diseños de algunas etiquetas que conservan cierto cariz regionalista, como la marca del perfume sevillano "Brisas del Ebro", presentado para la Exposición hispano-francesa de 1908 celebrada en Zaragoza. Lo que nos interesa resaltar de esta etiqueta es que, aun siendo una casa de Sevilla la creadora, identificó el fundamento aragonés del producto mediante un diseño -posterior a la mencionada Exposición- con una silueta femenina y, lo interesante, de fondo la mítica vista de la capital aragonesa del Puente de Piedra sobre el Ebro y la basílica del Pilar de fondo. También el perfume mallorquín "Flor d'Atmetler" incorporó a su etiqueta, en relación a su lugar de origen, una payesa vestida a la usanza de la isla con un ramo de almendro en la mano. O la tarjeta comercial de la Fábrica de Perfumería de J. Robillard y Cía. con una mujer ataviada con el traje tradicional femenino de la huerta de Valencia.

Asimismo, como advertimos en el resumen de este estudio, este interesante apartado de las representaciones artísticas para la propaganda comercial aún no está muy explotado dentro de la disciplina de las Humanidades, en concreto de la historia del arte que enmarca las imágenes sobre la identidad de la Región de Murcia, aunque en los últimos años, gracias también a los fondos de la Biblioteca Nacional de España y a los diversos archivos municipales o provinciales, encontramos una fuente importantísima que abarca diversos enfoques. Por reseñar uno de los últimos trabajos que han tratado estas cromolitografías de uso limitado y efímero encontramos una publicación de total actualidad de Carolina Naya Franco, profesora de Historia del Arte de la Universidad de Zaragoza, El arte de la Ephemera y la industria aragonesa (1850-1920), de $2019^{7}$.

En conclusión, lo verdaderamente importante de los ejemplos murcianos que hemos citado, pues ha sido el objetivo primordial en este estudio, es que podemos constar la existencia de un corpus identitario visual en base a algunos diseños de ephemera para fábricas u otras empresas de la primera mitad del siglo XX. Por lo que atestiguamos que en los diseños de estas etiquetas se volvieron a reutilizar los mismos iconos del pasado y, por consiguiente, se continuó alimentando el imaginario colectivo que se tenía de esta región desde las primeras décadas del romántico siglo XIX hasta prácticamente la actualidad: la importancia de su huerta a nivel nacional e internacional, tanto desde el punto de vista paisajístico como de producción comercial. Incluso se acrisoló definitivamente la marca "Murcia, Huerta de Europa" como principal foco exportador de frutas, verduras, hortalizas, conservas, etc., en el resto de Europa y América (Martínez Carrión, 1999).

Por otro lado, a excepción de los dos diseños realizados por renombrados pintores murcianos (Garay y Ros) para las etiquetas del Hotel Victoria y la fábrica de naranjas de José Manuel Meseguer, con la marca "The Noble-Man", todas las demás, aparte de no aparecer firmadas por ningún ilustrador gráfico, nos muestran un diseño simplista en el que se recurrió (nuevamente) a las imágenes icónicas de monumentos y tipos humanos de índole popular del siglo XIX de fotografías, grabados o litografías. Pero no por eso

\footnotetext{
${ }^{7}$ Aunque hemos intentado hacernos con este ejemplar para incluirlo dentro de este breve estudio, dadas las circunstancias mundiales que hemos vivido a causa del COVID-19 en este 2020, no hemos podido adquirirlo puesto que la editorial ha prorrogado su venta. Por tanto, hemos tenido a bien tener un reconocimiento a esta publicación que a ciencia cierta abrirá un interesante campo de investigación en otros territorios nacionales.
} 
estas etiquetas dejaron de ser menos importantes, pues el mensaje esencial que quisieron transmitir desde cada fábrica o comercio, patentar el origen de su producto en base al territorio, finalmente diferenció y homologó visualmente la marca de cada empresa dentro de los imaginarios de los circuitos de exportaciones nacionales e internacionales. En definitiva, a merced de todas las representaciones visuales de base románticocostumbrista se consiguió consolidar ciertos signos que marcaron, y aún siguen haciéndolo, la identidad de Murcia desde fuera, pero también desde dentro y que se han dilatado en el tiempo hasta nuestros días, también pasando a ser un sello y, en este caso, referente comercial.

\section{BIBLIOGRAFÍA}

Cánovas Belchí, J. (2016). Murcia en el imaginario fílmico francés: Adaptaciones cinematográficas de María del Carmen (Felíu y Codina, 1896) en la industria gala: Aux Jardins de Murcie (1923 y 1936). En El Greco en su IV Centenario: patrimonio hispánico y diálogo intercultural, 303-324.

Cos-Gayón, F. (1863). Crónica del viaje de sus Majestades y Altezas Reales a Andalucía y Murcia en septiembre y octubre de 1862. Madrid: Imprenta Nacional.

Álvaro Hernández Vicente, A. (2018). Don Diego Saavedra Fajardo: actos y festejos en la ciudad de Murcia por el tercer centenario de su nacimiento. En Yngenio et arte: elogio, fama y fortuna de la memoria del artista, 376-395.

Martínez Carrión, J.M. (1999). Agricultores e industriales en el negocio del pimentón, 1830-1935. Revista de Historia Económica, 1, 149-186.

Martínez Carrión, J.M. (2002). Economía de la Región de Murcia. Murcia: Consejería de Educación y Cultura de la Comunidad Autónoma de Murcia.

Ortiz García, C. (2012). Folclore, tipismo y política. Los trajes regionales de la Sección Femenina de la Falange. Gaceta de antropología, 28, s.p.

Páez Burruezo, M. (2012). Un ciclo pictórico regional. Murcia 1800-1930. Murcia: Pictografía.

Pérez Picazo, M. T. (1980). Historia. En Historia de la Región de Murcia. Murcia: Ediciones Mediterráneo, 1-179.

Ramos Frendo, E. M. (2008). Iconos del mundo clásico en la publicidad de las revistas ilustradas españolas (1915-1935). Imafronte, 19-20, 325-338.

Ramos Pérez, R. (2002). Ephemera: la vida sobre el papel. Introducción. En Centro Virtual Cervantes: https://cvc.cervantes.es/artes/muvap/sala4b/introduccion.htm

Ramos Pérez, R. (2011). El arte de la belleza. Madrid: Biblioteca Nacional de España. 